\title{
Molecular Determinants in Ulcerative Colitis - Epigenetics and Telomere Dysfunction
}

\author{
Ramesh P. Arasaradnam ${ }^{1,2}$ and Chuka U. Nwokolo ${ }^{1}$ \\ ${ }^{1}$ Department of Gastroenterology, University Hospital Coventry E Warwickshire, \\ Coventry \\ ${ }^{2}$ Clinical Sciences Research Institute, University of Warwick, Coventry \\ United Kingdom
}

\section{Introduction}

Ulcerative colitis (UC) is a chronic relapsing disease which runs a rather unpredictable clinical course. It usually starts in the $2^{\text {nd }}$ or $3^{\text {rd }}$ decade of life and is associated with an increased risk of bowel cancer. Unlike Crohn's disease, there is a relative paucity of basic science research as to the molecular determinants that govern mucosal inflammation and subsequent risk of developing colon cancer. Genetic linkage studies in inflammatory bowel disease (IBD) traditionally have focussed on candidate genes and haplotypes in at risk individuals but emerging evidence would also suggest the importance of epigenetics. Epigenetics is the heritable alteration in gene expression but without alteration in DNA sequence. Consequently the human epigenomic project has now been established. In this chapter we will discuss emerging epigenetic changes in UC and also newer molecular targets that have come to the fore such as telomere dysfunction which, may be used as putative biomarkers.

One of the more common epigenetic alterations includes DNA methylation of the gene promoter. Much work has focussed on colon cancer but our group and others have identified gene promoter DNA hypermethylation in individuals with UC. Critically these epigenetic markings affect key tumour suppressor genes which, are then silenced as a result of hypermethylation. This therefore may be a potential pathway by which those with UC develop colon cancer and will be explored in further detail in this chapter.

Similarly telomere dysfunction has been well studied in colon cancer and the ageing population but lacking in those with UC. Telomeres are the end of chromosomes and are long at birth but get shorter with age. At a critical length the telomere signals the end of a cell's life (apoptosis) but some cells can escape death and instead become neoplastic. There is reduction in telomerase enzyme (key regulator in telomere length) in UC as well as alteration in key telomere binding proteins (TBP). One such protein is TRF2 which is a protein that helps protect telomeres from degrading with age and inflammation thus delaying the inevitable changes described earlier. Patients with ulcerative colitis appear to have a shortage of this protein and the longer the duration of the disease the less the protein. There is also a suggestion that it may also be altered with therapy (immune-modulating) drugs used to treat UC. TRF2 may yet provide a candidate protein for a biomarker which we will discuss together with the role of other TBPs and its relationship with UC disease activity. 
This chapter will cover in detail a literature review and summary of current and developing work in our lab and others using the headings outlined below:

\section{Epigenetics}

Epigenetic alterations are heritable alterations in gene expression not mediated by alteration in DNA sequence i.e. the message is altered but not the gene itself [Jaenisch et al 2003]. Such changes include DNA methylation and are among the most common molecular alterations in human cancers including colorectal cancer. Other epigenetic changes include histone acytelation and protein ubuiquitination. For the purpose of this chapter we will concentrate on DNA methylation as it is the most common epigenetic marking and has demonstrable changes in UC.

DNA methylation involves the addition of a methyl group to the carbon-5 position of cytosine residues and is the only common covalent modification of human DNA. It occurs almost exclusively at cytosines that are followed immediately by guanine (CpG dinucleotides). The majority of the genome displays a depletion of $\mathrm{CpG}$ dinucleotides and those that are present are nearly always methylated. Conversely, small stretches of DNA known as $C p G$ islands (usually located within the promoter regions of human genes), whilst rich in CpG dinucleotides, are nearly always free of methylation. Methylation of CpGs within these islands are associated with transcriptional inactivation of the corresponding gene, which, appears to be tissue specific. In colon cancer (CRC) for example, aberrant methylation resulting in gene silencing can occur in important tumour suppressor genes such as $p 16^{I N K 4 a}$ [Merlo et al 1995]. Both genomic DNA hypomethylation as well as gene specific (promoter) hypermethylation have been observed in CRC. DNA methylation is vital in controlling gene transcription through histone modification. Such conformational changes can induce either activation through acetylation for example or repression due to methylation of a histone residue - Figure 1.

Although the methylation profile within the human genome is as yet undetermined, it is estimated that $70 \%$ of $\mathrm{CpG}$ dinucleotides are methylated in mammals. Hypermethylation in gene promoter regions are associated with transcriptional silencing which is at least as common as inactivation of tumour suppressor genes through DNA mutations [Jones et al 2002]. Aberrant hypermethylation is thought to be an early event in CRC as it is detectable in early precursor lesions e.g. Aberrant Crypt Foci (ACF). Such aberrant changes can occur in chronically inflamed tissue which, if involves key tumour suppressor genes may have deleterious effects.

\subsection{Age related DNA methylation}

Genomic loss of methylation has been known to occur with ageing. This phenomenon has yet to be shown in the normal ageing colon until recently [Arasaradnam 2007]. Most of the attention surrounding DNA methylation has been centred on gene specific methylation. In the colon, age related methylation accounts for $70 \%$ of aberrant gene specific methylation events. This process is thought to be a non-stochastic i.e. predictable event and is tissue specific. For example, methylation of the ESR1 (tumour suppressor gene) promoter has been shown to increase with age in normal human colon and is present also in adenomas thus supporting the idea that epigenetic gene silencing is an early event [Issa et al 1994]. Thus it is apparent that methylation homeostasis is perturbed with ageing but it is not known if ageing is accelerated as a result of if there are consequential effects on other factors such as telomere attrition for example (discussed later). 

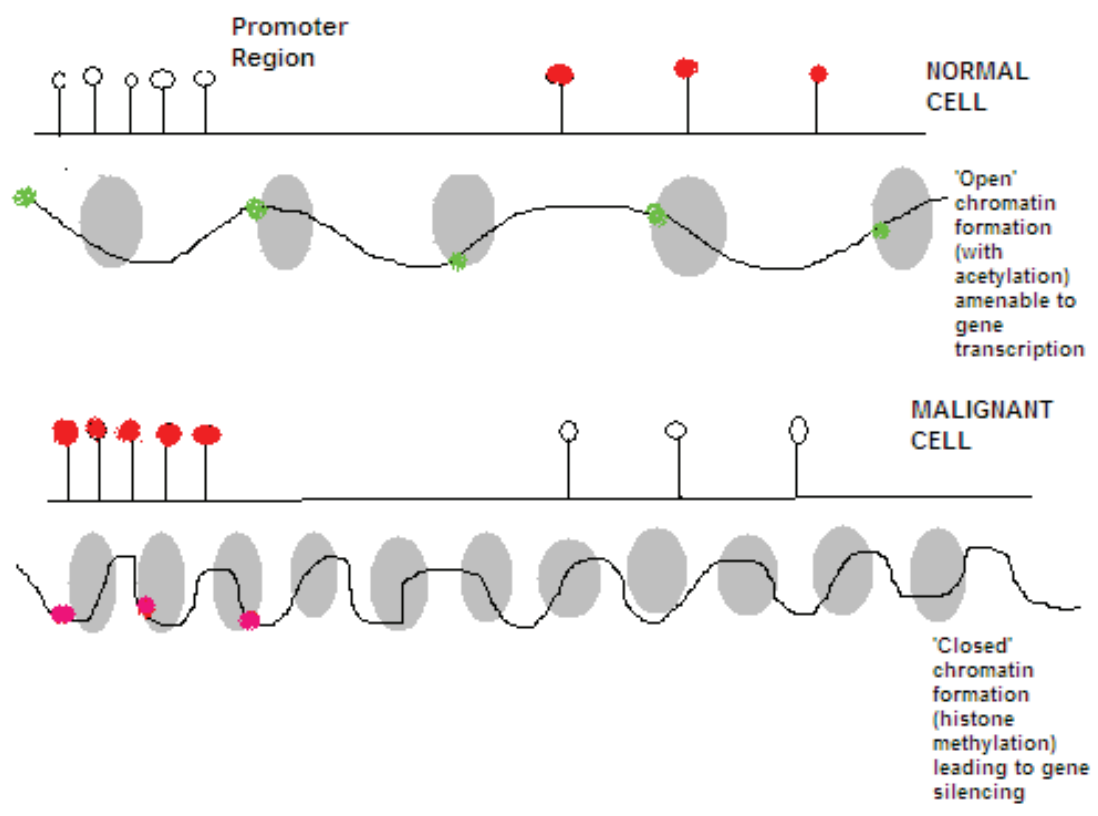

Fig. 1. A stretch of genomic DNA in normal and malignant cell. The white pins denote unmethylated $\mathrm{CpG}$ sites within the promoter region of normal cells which become methylated (red pins) during malignant transformation. Conversely, globally the remaining CpG dinucleotides are methylated in the normal cell (red pins) and unmethylated in malignancy (white pin). The nucleosome (DNA and histones) shown as grey ovals depicts the open and closed formation which affects gene transcription either through acetylation (green dots) which results in activation or repression due to methylation of certain histone residues (pink dots)

In the aged, as with chronic inflammation (e.g. ulcerative colitis), a critical threshold of random accumulation of somatic mutations is thought to be reached leading to the development of cancer. However it is more likely due to a combination of effects such as cumulative mutational load, epigenetic gene silencing, telomere dysfunction and even altered stromal environment [dePinho, 2000]. The perceived key genes regulating this process have been studied but with inconsistent results.

\subsection{Influence of dietary factors on DNA methylation}

Epigenetic changes such as DNA methylation are potentially reversible and gene expression can be re-established. The active ingredient in Green Tea (EGCG) provides a good example of reversal of aberrant methylation with a dietary food component reaffirming the role of diet in cancer prevention. The concept of dietary intervention gained further momentum following evidence in animal models and epidemiological studies in humans showing that folate status can modulate risk of development of colorectal adenoma and cancer. The role of folate in UC is discussed further in section 2.3.1. For detailed review on mechanisms of diet influencing epigenetics specifically colorectal carcinogenesis please see reference [Arasaradnam et al 2008]. 


\subsection{DNA methylation in UC}

Altered DNA methyl transferase (DNMT) activity, histone modification and exogenous insults such as diet have been postulated to result in genomic DNA methylation but their relative importance in human colonic disease is not well understood (Wilson et al. 2007). Apart from folate, little is known if environmental factors or lifestyle factors for example smoking patterns, alcohol consumption and diet could influence genomic DNA methylation. Furthermore, it would also be important to determine genomic DNA methylation in other colonic disease groups - chronic mucosal inflammation, including those which predispose to increased risk of CRC e.g. ulcerative colitis.

\subsubsection{DNA global methylation}

$\mathrm{UC}$ is a chronic inflammatory condition with an increased risk of developing CRC (Crohn, Ginzburg et al. 1984; Ransohoff 1988) especially in those diagnosed at a younger age and with greater extent of disease (Ekbom et al. 1990). Genomic instability has been proposed as a likely explanation for the observed UC associated CRC risk. Examples of molecular determinants used to assess risk in UC include cellular proliferation, genomic DNA methylation (Gloria et al. 1996, Arasaradnam et al 2010) and microsatellite instability (Tahara, Inoue et al. 2005) amongst others.

We have shown that using tritium labelled experiments, $3[\mathrm{H}]$ dCTP incorporation into DNA was lower in UC patients compared to age and sex matched controls (Arasaradnam et al 2010). In other words, there was relative genomic hypermethylation in UC subjects compared with healthy controls. This finding is in contrast with the only other report a decade ago of genomic hypomethylation in UC patients (Gloria et al. 1996). Here the authors report genomic hypomethylation in 26 patients with UC compared to 11 controls using the methyl acceptance assay. This assay has several limitations (indirect, semi-quantitative and prone to false positives due to damaged DNA templates) (Pufulete et al. 2005). They also speculate that low levels of S-Adenosyl Methionine (SAM); universal methyl donor in active UC coupled by increased cell proliferation may impair DNA methylation status. Conversely we have shown that although folate status was lower in UC subjects, it was still within the normal reference range. Apart from the different methods employed to quantify genomic DNA methylation, the other significant difference was in the proportion of UC patients with active disease. The SCAI is a validated scoring system used to identify patients that have relapsed after being in remission (Walmsley et al. 1998). Of note in our study, 5 patients (20\%) had active disease as opposed to $12(50 \%)$ in the study by Gloria et al - this is likely to be an important contributory factor especially as rectal mucosal cells have been shown to undergo increased cellular proliferation (Gloria et al. 1996) when disease is active and hence incur greater DNA damage. Interestingly, no association was seen with age at diagnosis, duration of disease and number of flares with genomic DNA methylation.

Although red cell folate levels of UC patients in our study were lower than controls, it was within normal limits. Previous work (Spiers A et al unpublished) has shown good correlation between red cell folate status and mucosal folate levels. Lower levels of folate have been attributed to variation in dietary intake, interaction with certain medications (sulphapyridines) and increased cell proliferation (Biasco 2005). The normal folate level and relative hypermethylation profile in UC patients (mainly quiescent/ mild disease and with significantly lower total leucocyte count than controls) may be a consequence of lower rectal cell proliferation and increased cell renewal hence altering the genomic DNA methylation profile favourably. A further novel finding is that almost $16 \%$ of variability in genomic DNA 
methylation between UC subjects and controls could be explained by BMI alone (Arasaradnam 2007). Thus lower BMI is associated with genomic hypermethylation which provides support for existing evidence of increasing body fatness being associated with increased colon cancer risk (Friedenreich et al. 2006).

The lower folate status and relative genomic hypermethylation observed in UC subjects corroborate a recent report showing a protective effect of low folate status on risk of CRC (Van Guelpen et al. 2006). The biological role of folate and DNA methylation in UC is not as clear as initially thought and the question of its protective role against $\mathrm{CRC}$, if any, remains unclear (Arasaradnam 2010).

\subsubsection{Gene specific methylation in UC}

Epigenetic studies especially in colon carcinogenesis have focussed mainly on gene specific methylation. This is not remarkable as gene specific hypermethylation can result in reduced gene expression/ silencing with consequent detriment to the colonocyte, particularly, if key genes such as tumour suppressor genes (APC, p53, p16INK4a, p14ARF and ESR-1) are involved (Issa et al. 1994; Merlo et al. 1995; Esteller 2002). Indeed, most genes hypermethylated in tumours originate from the gastrointestinal tract - oesophagus, stomach and colon with significantly less reported in other tumour types e.g. ovarian (Esteller et al. 2001). CpG island methylation affects several genes including tumour suppressor genes ( $p 16^{\text {INK4a }}, p 14^{A R F}, A P C$, p53), silencing of DNA mismatch repair genes ( $\left.h M L H 1, O^{6}-M G M T\right)$, possible loss of function of apoptosis genes (DAPK, APAF-1) and altered carcinogen metabolism (GSTP1) (Esteller 2002).

Most studies in UC have considered DNA hypermethylation of two genes - Oestrogen receptor gene $(E S R-1)$ and Tumour suppressor gene candidate $3(N-33)$ - both putative tumour suppressor genes. ESR-1 which is located on chromosome 6 has been shown to be hypermethylated in the colonic mucosa of those with CRC and to a lesser extent in normal individuals (Ahuja et al. 1998). In cell culture, de-methylation of ESR-1 has been shown to suppress growth and hence has been proposed to be putative tumour suppressor gene (Issa et al. 1994). N-33, also a putative tumour suppressor gene is located on chromosome 8 and has been shown in vitro to result in growth suppression of cancer cells. One small study has shown hypermethylation of $\mathrm{N}-33$ in both tumour tissue as well as in the normal colon (Ahuja et al. 1998). Moreover promoter hypermethylation of both these genes have been shown to be age related.

Little is known about the mucosal inflammatory effect of UC on gene specific methylation. Using the COBRA assay, Issa and colleagues found higher methylation of ESR-1 in 12 UC subjects with high grade dysplasia or cancer compared with 6 UC patients without dysplasia. In that study, methylation levels were comparable for UC patients without dysplasia and healthy controls $(n=5)$. A later study by Tominaga et al (2005), also using the COBRA method, reported higher levels of ESR-1 methylation in the neoplastic epithelium of UC patients compared with non-neoplastic tissue ( $25 \%$ vs $4 \%$ respectively). There were also higher levels of methylation in the distal colon compared with the proximal colon but only in UC patients with neoplasia. No healthy controls were used. Table 1 summarises the studies on gene specific methylation in UC.

Specifically promoter gene methylation for both ESR-1 and N-33 were significantly higher in the macroscopically normal epithelium of UC subjects compared with age and sex matched controls (Arasaradnam et al 2010). There was no evidence of dysplasia (confirmed histologically) and importantly on subsequent follow up at three years, no cancers were identified. A smaller study by Issa et al. showed no difference in ESR-1 methylation between controls $(n=5)$ and UC subjects without dysplasia $(n=6)$. This lack of a difference may be 
explained by the relatively small sample size (only 6 UC patients without dysplasia and 5 controls) compared with the study by Arasaradnam et al. which recruited 68 patients (24 UC subjects and 44 age and sex matched controls). Furthermore, the clinical characteristics of the UC subjects in the study by Issa et al. were not described in detail. For example, it is not known whether the UC subjects without dysplasia had less active, less extensive disease and shorter duration of disease compared with those with dysplasia. Importantly no relationship between age at diagnosis, disease duration, number of flare-ups, SCCAI score or disease extent with promoter methylation of ESR-1 or N-33 was identified (Arasaradnam et al 2010).

\begin{tabular}{|c|c|c|c|c|}
\hline $\begin{array}{l}\text { Study } \\
\text { Characteristics }\end{array}$ & $\begin{array}{l}\text { (Issa, Ahuja et al. } \\
\text { 2001) }\end{array}$ & $\begin{array}{l}\text { (Fujii, Tominaga } \\
\text { et al. 2005) }\end{array}$ & $\begin{array}{l}\text { (Tominaga, Fujii } \\
\text { et al. 2005) }\end{array}$ & $\begin{array}{l}\text { (Arasaradnam et } \\
\text { al. 2010) }\end{array}$ \\
\hline Gene & $\begin{array}{l}\text { ESR-1, p16, } \\
\text { hMLH, CSPG2 }\end{array}$ & $E S R-1$ & $E S R-1$ & $\begin{array}{l}\text { ESR-1, MYOD-1, } \\
\text { N-33 }\end{array}$ \\
\hline Sample size & 21 & 30 & 18 & 68 \\
\hline Patient & 12-HGD/cancer & 13 with cancer & 8 with cancer & $24 \mathrm{UC}$ \\
\hline Characteristics & $\begin{array}{l}\text { 6- No Dysplasia } \\
5 \text { - controls }\end{array}$ & $\begin{array}{l}17 \text { without } \\
\text { cancer }\end{array}$ & $\begin{array}{l}10 \text { without } \\
\text { cancer }\end{array}$ & $\begin{array}{l}44 \text { age \& sex } \\
\text { matched controls }\end{array}$ \\
\hline Assay Method & COBRA & MSP & COBRA & COBRA \\
\hline Findings & $\begin{array}{l}\text { Higher } \\
\text { methylation of } \\
\text { ESR-1,P16 \& } \\
\text { CSPG2 in UC with } \\
\text { HGD/cancer. } \\
\text { Controls had } \\
\text { similar levels to } \\
\text { UC with dysplasia }\end{array}$ & $\begin{array}{l}\text { Higher ESR-1 } \\
\text { methylation in } \\
\text { UC with cancer } \\
\text { compared to } \\
\text { without. }\end{array}$ & $\begin{array}{l}\text { Higher ESR-1 } \\
\text { methylation in } \\
\text { UC with cancer } \\
\text { compared to } \\
\text { without. } \\
\text { Methylation } \\
\text { gradient in colon } \\
\text { only for those } \\
\text { with cancer }\end{array}$ & $\begin{array}{l}\text { Higher ESR-1, N33 } \\
\text { methylation } \\
\text { compared to } \\
\text { controls. Lower } \\
\text { methylation for } \\
\text { MYOD-1. } \\
\text { Less smokers } \\
\text { among UC }\end{array}$ \\
\hline $\begin{array}{l}\text { Relationship to } \\
\text { UC disease } \\
\text { characteristics }\end{array}$ & - & $\begin{array}{l}\text { No relationship } \\
\text { between ESR-1 } \\
\text { and } \\
\text { inflammatory } \\
\text { activity }\end{array}$ & $\begin{array}{l}\text { No relationship } \\
\text { between ESR-1 } \\
\text { and } \\
\text { inflammatory } \\
\text { activity }\end{array}$ & $\begin{array}{l}\text { No relationship } \\
\text { btw ESR-1, MYOD- } \\
1, N-33 \text { and disease } \\
\text { activity, duration, } \\
\text { SCAI score, no. of } \\
\text { flares or site. }\end{array}$ \\
\hline
\end{tabular}

HGD = High Grade Dysplasia; MSP = Methylation Sensitive PCR (MSP is a sensitive method to detect methylation but is not quantitative)

Table 1. Summary of studies on gene specific methylation in UC.

The findings of CpG hypermethylation of the putative tumour suppressor genes N-33 and ESR-1 in normal tissue suggests that inactivation through methylation of these specific putative tumour suppressor genes may not be associated with development of CRC in UC patients. The functional role of $\mathrm{N}-33$ in UC remains unknown as yet.

\subsubsection{DNA methylation in UC and colon cancer}

The central pathway (normal epithelium $\rightarrow$ adenoma $\rightarrow$ carcinoma) are a result of linear accumulation of genetic mutations and/or chromosomal instability in the wnt signalling pathway. Mutation of the APC gene and resultant truncated APC products are unable to bind to $\beta$-catenin resulting in Wnt signalling dysfunction - the latter involved in progression 
of most sporadic and certain hereditary CRC. It should be noted however that APC inactivation is not always the first genetic event and that $k$-Ras mutations which have been observed in normal colonic mucosa as well as in aberrant crypt foci may precede this (Jan Willem 2000). CpG methylation is thought to be an early event and may even initiate tumourogenesis since it is detected in precursor lesions such as Aberrant Crypt Foci (ACF) and adenomatous polyps (Goelz et al. 1985). Consequently Esteller et al (2000) has proposed the role of tumour suppressor gene silencing through hypermethylation early in the pathway.

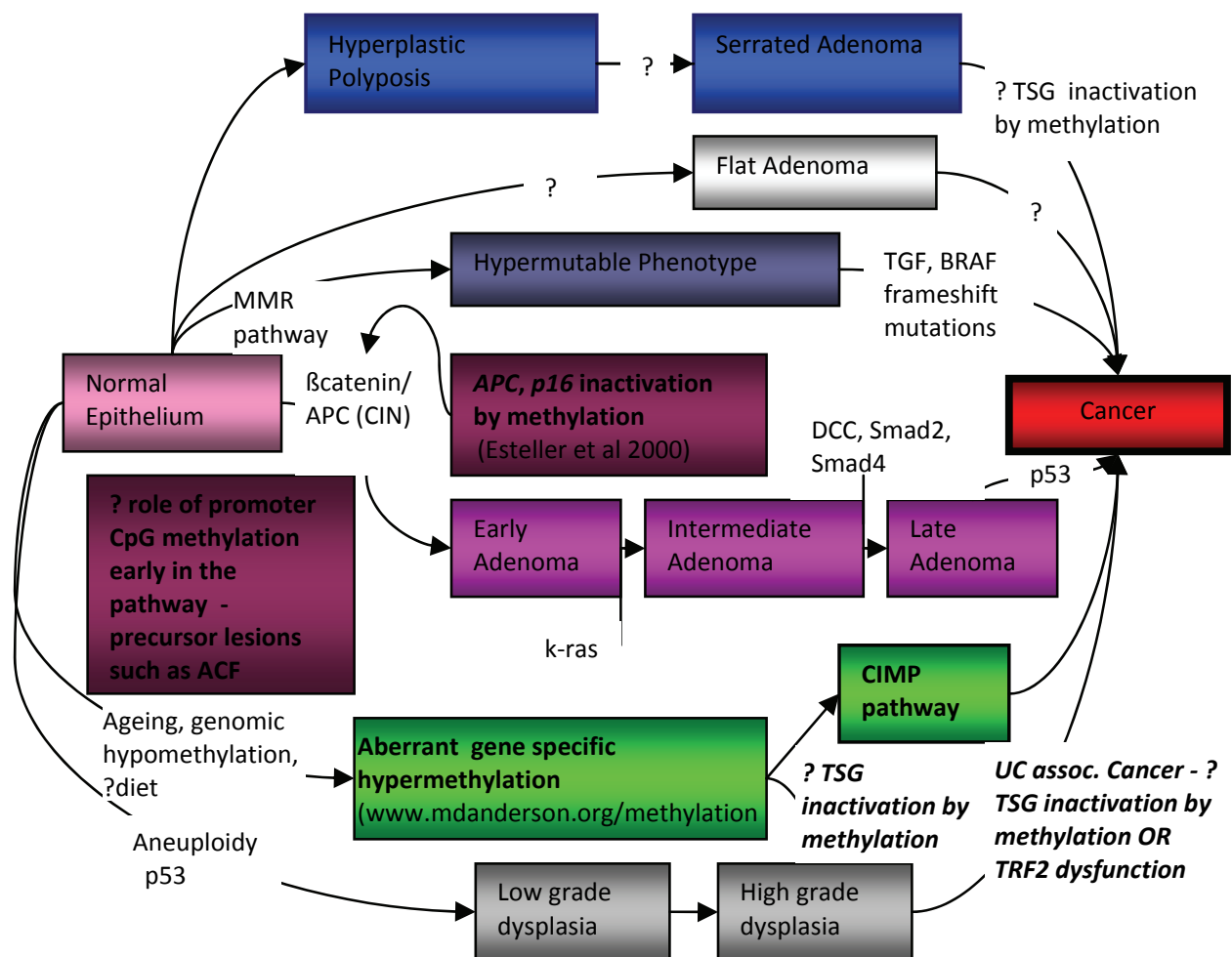

$\mathrm{APC}=$ Adenomatous Polyposis Coli $\mathrm{CIMP}=\mathrm{CpG}$ island methylator phenotype $\mathrm{CIN}=$ Chromosomal Instability; DCC $=$ Deleted in Colon cancer; $\mathrm{Smad}=$ mothers against decapentaplegic homolog 2,4; MMR $=$ Mismatch Repair; TGF $=$ Tumour Growth Factor; BRAF $=$ (v-raf) oncogene homolog B1; TSG = Tumour Suppressor Gene; UC = Ulcerative colitis; TRF2 = Telomere Repeat Binding Factor

Fig. 2. Schematic model for genetic alterations in the development of CRC - modified from Fearnhead et al 2001. Incorporates updates of the model to demonstrate possible roles for methylation/ telomere dysfunction in the UC - CRC pathway

Although not well understood, certain genes appear susceptible to silencing through hypermethylation. A subset of genes which have particularly high methylation levels have been identified in sporadic colon cancers and hence the term $\mathrm{CpG}$ island methylator phenotype (CIMP) has been coined. Certain subsets of hyperplastic polyps (although the precise genetic alterations are unknown) appear to have potential for malignant transformation through the hyperplastic poly $\rightarrow$ serrated adenoma $\rightarrow$ adenocarcinoma sequence. This has been coined the 'methylator pathway' (Jass 2004). Similarly, the genetic 
alterations in the progression of flat adenomas (Paris type 0/11 clinical classification) to cancer remain elusive. In ulcerative colitis associated cancers unlike sporadic cancers, p53 mutations appear to be an early event. It is not clear what triggers the progression from high grade dysplasia to cancer but it is possible that aberrant methylation of tumour suppressor genes or telomere dysfunction could initiate this - see proposed pathway in Figure 2.

\section{Telomere and telomere binding proteins}

Chromosome instability in colon epithelial cells and peripheral blood lymphocytes (PBLs) has been described in ulcerative colitis (Loeb et al 1999). Telomeres are specialized structures that cap and protect chromosome ends. They are made up of a specific sequence of DNA repeats and form a T-loop structure which is stabilized by telomere associated proteins. Disruption of the T-loop structure causes the telomere to be recognised as a DNA double strand break, activates the DNA repair mechanism leading to telomere fusions and chromosome instability usually followed by apoptosis or senescence (Karlseder 2003). Telomere shortening occurs with each cell division and as a result of cellular stress. This causes depletion of telomeric repeats and telomere binding proteins threatening the stability of the T-loop structure. Telomere dysfunction also follows decreased expression of the telomere proteins which bind double stranded DNA. This causes disruption of the T-loop structure without significant telomere shortening and is known as telomere uncapping (BenPorath et al 2004). Dysfunction can also occur with loss of the 3' overhang, a single stranded stretch of DNA at the very end of the telomere protected by proteins known as telomere binding proteins such as TRF1, TRF2, TPP1, TIN2, RAP1 like POT-1 $(15)(4,16)$. These proteins have been described to influence telomere maintenance (de Lange 2005) - Figure 3.

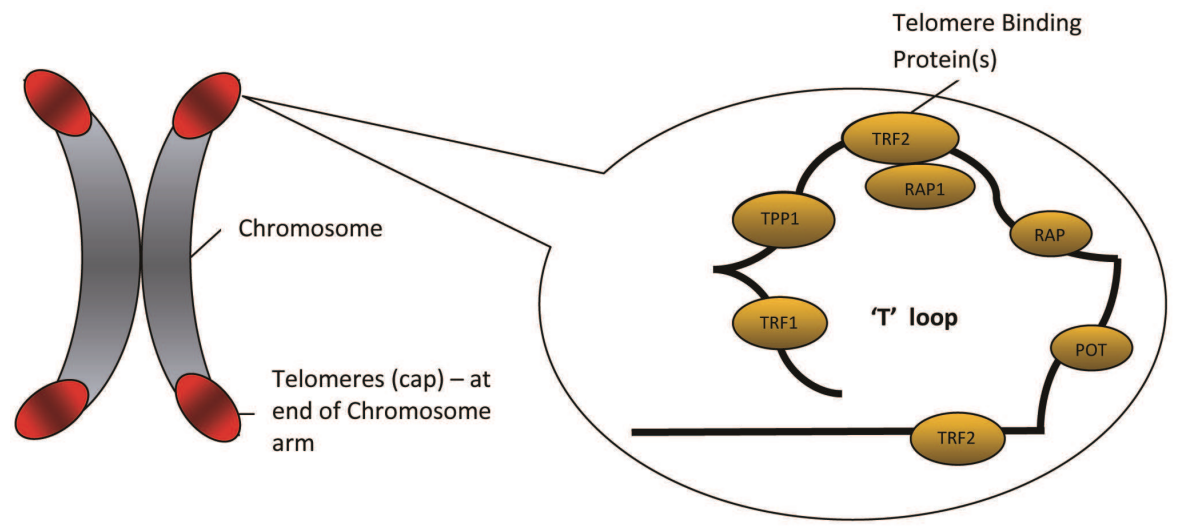

Fig. 3. Telomere caps at the end of chromosomes. Magnified view showing ' $\mathrm{T}$ ' loop structure of 'Shelterin complex comprising the Telomere binding proteins

\subsection{Telomere dysfunction in UC}

The two main forms of inflammatory bowel disease (IBD), ulcerative colitis (UC) and Crohn's disease $(\mathrm{CD})$, are characterised by chronic intestinal inflammation and risk of progression to colon cancer (Ransohoff 1988). One proposed cause of the latter characteristic is chromosome instability, since the rearrangement of genetic material can lead to activation of oncogenes, loss of tumour suppressor genes and other changes that lead to uncontrolled cell growth. 
Since genomic instability in peripheral blood mononuclear cells (PBMCs) has been used as a biomarker for global cancer risk in a number of diseases (Cottliar et al 2000), the latter observation suggests the possibility of a chromosome instability syndrome in UC that could affect all tissues. One possible cause of chromosome instability aside from genomic DNA methylation is telomere dysfunction. In eukaryotic cells, telomeres are maintained by telomerase and the sub complex of telomere binding proteins. The chromosome instability observed in UC PBMC includes telomere fusions, suggesting the involvement of these structures in its generation. Other observations linking telomeres and UC include decreased telomerase in the colitic colonic mucosa (Ussleman et al 2001), colitis-like ulcerations of the bowel in the telomerase knockout mouse (Lee et al 1998) and shortened telomeres in UC patients showing evidence of dysplasia (Arasaradnam et al 2009). Furthermore telomere shortening is not accelerated in peripheral blood mononuclear cells of UC patients compared with controls and therefore cannot be the mechanism by which chromosome instability arises in these cells (Getliffe et al 2005). Of particular note is the observation in rectal fibroblasts of UC patients showing slower telomere shortening particularly in those with late onset UC. This suggests those who develop UC later in life perhaps have more efficient anti-oxidant systems that protect against telomere damage. (Getliffe et al 2006)

\subsection{Role of telomere binding proteins (TBPs) in UC}

The telosome/shelterin complex consists of important regulatory telomere binding proteins to include TPP1 (tripeptidyl peptidase1 - formerly PTOP/PIP1/TINT1), POT1 (protection of telomere 1), TIN2 (TRF1 interacting nuclear factor 2), RAP1 (repressor activator protein), TRF1 (telomere repeat binding factor 1) and TRF2 (de Lange 2005).Telomere repeat binding factor 2 (TRF2) is a double stranded DNA binding protein which stabilizes the telomere Tloop. Cells lacking functional TRF2 have an extremely striking chromosome instability phenotype including frequent telomere fusions and erosion of the $3^{\prime}$ overhang, but no significant telomere shortening (de Lange 2002). Therefore decreased expression of TRF2 in UC peripheral mononuclear cells, might explain the chromosome instability observed in these cells. More recent data also suggests that aside from maintaining telomeres, TRF2 may also be involved in the repair of DNA damage, including that which occurs at dysfunctional telomeres (Bradshaw et al 2005).

\subsubsection{Telomere Repeat Binding Factor 2 (TRF2)}

TRF2 mRNA expression is significantly decreased in activated T lymphocytes in both UC and $C D$, suggesting possible telomeric deficiency of this protein which could lead to destabilisation of the T-loop structure in these cells (da Silva et al 2010). This telomere dysfunction could then cause activation of DNA damage response to repair what is perceived as a double strand break resulting in the telomere fusions previously observed in UC PBMCs. Thus decreased TRF2 mRNA levels in circulating T lymphocytes in IBD could be a putative bio-marker for potential active or refractory disease. It is uncertain if similar changes are present in the cells of the colonic mucosa in IBD where chromosomal abnormalities are thought to precede dysplasia and malignant change.

The finding of low levels of TRF2 in IBD T lymphocytes makes it unlikely that this protein has a significant role in DNA repair mechanisms in this disease. An alternative explanation is that the cells have entered a phase of early senescence hence there is down regulation of telomere binding proteins (Risqué et al 2011). Telomere attrition has been demonstrated in 
colonic epithelium of patients with ulcerative colitis which, could potentially initiate senescence (Risque et al 2008).

Senescence is thought to act as a tumour suppressor forcing cells to undergo apoptosis rather than uncontrolled cellular proliferation which leads to cancer. mRNA expression levels of RAP1 for example is lower in activated T lymphocytes in UC (da silva et al 2010). RAP1 is closely regulated by TRF2 which in turn is stabilised by TIN2 to form a bridge across telomeric DNA. The reduced RAP1 expression in activated T lymphocytes hints at premature cellular senescence in circulating activated lymphocytes. It is yet unknown if these findings are replicated at mucosal level. Of interest is the observation of a positive association between RAP1 gene expression with 5 - aminosalicylate therapy (da silva et al 2010). It is possible that 5 - aminosalicylate therapy may help stabilise the RAP1/ TRF2/ TIN2 sub complex by increasing its expression thus providing better telomere dynamics in UC. This in turn may explain the clinical observation of the protective effect of 5 - aminosalicylate therapy in UC associated cancer providing further support for its chemo-prophylactic use (Rubin et al 2006). It is evident that the telomeric milieu at the chromosome end zone is intricately balanced with telomerase and telomere binding factors being the key players. The precise role and function of individual telomere binding proteins are largely unknown but it is clear that its coordinated interaction with telomere DNA is vital to maintaining telomere stability. Perturbance, as a result of local (mucosal) inflammation within this delicate sub complex of telomere proteins will, not surprisingly cause telomere dysfunction.

\section{Conclusion}

Further evaluation to measure $\mathrm{N}-33$ expression (at mRNA and protein level) as well as to evaluate further epigenetic marking of tumour suppressor genes in larger UC cohorts including those with dysplasia and UC associated cancer are required. This will help elucidate further the role of DNA methylation in particular within the UC-CRC pathway. Additionally, studies to determine associations with habitual dietary intake are required the latter being an important variable given the modifiable effect of diet on DNA methylation. Finally the role of TBPs in particular mucosal TRF2 in UC patients in the clinical setting of progressive dysplasia and colon cancer will be vital to elucidate its role as a putative biomarker of cancer risk.

\section{References}

Ahuja, N., Q. Li, et al. (1998). Aging and DNA methylation in colorectal mucosa and cancer. Cancer Res 58(23): 5489-94.

Arasaradnam RP (2007). Dietary factors and mucosal biomarkers of colon cancer risk. British Library, London (PhD thesis)

Arasaradnam RP, Commane D, Bradburn D, Mathers JC (2008). A Review of dietary factors and its influence on DNA methylation in colorectla carcinogenesis. Epigenetics JulAug;3(4):193-8.

Arasaradnam RP, Khoo KTJ, Bardburn M et al.(2009) Telomere attrition in colorectal mucosa of patients with Ulcerative Colitis (abs). Gut ;A100:257

Arasaradnam RP (2010). The conundrum of folate and colorectal cancer (CRC) risk. Eur J Clin Nutr. Dec; 64(12):1501

Arasaradnam RP, Khoo KTJ, Bradburn M, Mathers JC, Kelly S (2010). DNA methylation of ESR-1 and N-33 in colorectal mucosa of patients with Ulcerative colitis (UC). Epigenetics Jul;5(5):422-6 
Ben-Porath I, Weinberg RA (2004). When cells get stressed: an integrative view of cellular senescence. J Clin Invest ;113:8-13.

Biasco, G. and M. C. Di Marco (2005). Folate and prevention of colorectal cancer in ulcerative colitis. Eur J Cancer Prev 14(4): 395-8.

Bradshaw PS, Stavropoulos DJ, Meyn MS (2005). Human telomeric protein TRF2 associates with genomic double-strand breaks as an early response to DNA damage. Nat Genet; 37:193-7.

Crohn, B. B., L. Ginzburg, et al. (1984). Landmark article Oct 15, 1932. Regional ileitis. A pathological and clinical entity. By Burril B. Crohn, Leon Ginzburg, and Gordon D. Oppenheimer. JAMA 251(1): 73-9.

Cottliar A, Fundia A, Boerr L, et al (2000). High frequencies of telomeric associations, chromosome aberrations, and sister chromatid exchanges in ulcerative colitis. Am J Gastroenterol ;95:2301-7.

da Silva N, Arasaradnam R, Getliffe K et al (2010). Altered mRNA expression of telomere binding proteins (TPP1, POT1, RAP1, TRF1, TRF2) in Ulcerative colitis and Crohn's disease. Dig Liver Dis 42(8):544-8

de Lange $T$ (2005). Shelterin: the protein complex that shapes and safeguards human telomeres. Genes Dev 15;19(18):2100-10

de Lange T(2002). Protection of mammalian telomeres. Oncogene ;21:532-40.

DePinho, R. A. (2000). The age of cancer. Nature 408(6809): 248-254.

Ekbom, A., C. Helmick, et al. (1990). Ulcerative colitis and colorectal cancer. A populationbased study. N Engl J Med 323(18): 1228-33.

Esteller, M., A. Sparks, et al. (2000). Analysis of Adenomatous Polyposis Coli Promoter Hypermethylation in Human Cancer. Cancer Res 60(16): 4366-4371.

Esteller, M., P. G. Corn, et al. (2001). A Gene Hypermethylation Profile of Human Cancer. Cancer Res 61(8): 3225-3229.

Esteller, M. (2002). CpG island hypermethylation and tumor suppressor genes: a booming present, a brighter future. Oncogene 21(35): 5427-40.

Fearnhead, N. S., M. P. Britton, et al. (2001). The ABC of APC 10.1093/hmg/10.7.721. Hum. Mol. Genet. 10(7): 721-733.

Friedenreich, C., T. Norat, et al. (2006). Physical Activity and Risk of Colon and Rectal Cancers: The European Prospective Investigation into Cancer and Nutrition. Cancer Epidemiol Biomarkers Prev 15(12): 2398-2407.

Fujii, S., K. Tominaga, et al. (2005). Methylation of the oestrogen receptor gene in nonneoplastic epithelium as a marker of colorectal neoplasia risk in longstanding and extensive ulcerative colitis. Gut 54(9): 1287-1292.

Getliffe KM, Al Dulaimi D, Martin-Ruiz C, et al (2005). Mononuclear telomere dynamics and telomerase activity in inflammatory bowel disease: effect of drugs and smoking. Aliment Pharmacol Ther; 21:121-31.

Getliffe KM, Martin-Ruiz C, Passos JF, von-Zglinicki, Nwokolo C (2006). Extended lifespan and long telomeres in rectal fibroblasts from late-onset ulcerative colitis patients. Eur J Gastroenterol Hepatol 18(2):133-41

Gloria, L., M. Cravo, et al. (1996). DNA hypomethylation and proliferative activity are increased in the rectal mucosa of patients with long-standing ulcerative colitis. Cancer 78(11): 2300-6.

Goelz, S. E., B. Vogelstein, et al. (1985). Hypomethylation of DNA from benign and malignant human colon neoplasms. Science 228(4696): 187-90.

Issa, J. P., Y. L. Ottaviano, et al. (1994). Methylation of the oestrogen receptor CpG island links ageing and neoplasia in human colon. Nat Genet 7(4): 536-40. 
Issa, J.-P. J., N. Ahuja, et al. (2001). Accelerated Age-related CpG Island Methylation in Ulcerative Colitis. Cancer Res 61(9): 3573-3577.

Jaenisch, R. and A. Bird (2003) Epigenetic regulation of gene expression: how the genome integrates intrinsic and environmental signals. Nat Genet. 2003;245-254

Jan Willem, A. (2000). Molecular interactions in the Vogelstein model of colorectal carcinoma. The Journal of Pathology 190(4): 412-416.

Jass, J. R. (2004). Hyperplastic polyps and colorectal cancer: is there a link? Clin Gastroenterol Hepatol 2(1): 1-8.

Jones, P. A. and S. B. Baylin (2002). The Fundamental Role of Epigenetic events in Cancer. Nature Reviews Genetics 3(6): 415-428.

Karlseder J (2003). Telomere repeat binding factors: keeping the ends in check. Cancer Lett; 194:189-97

Lee HW, Blasco MA, Gottlieb GJ, et al (1998). Essential role of mouse telomerase in highly proliferative organs. Nature; 392:569-74.

Loeb KR, Loeb LA (1999). Genetic instability and the mutator phenotype. Studies in ulcerative colitis. Am J Pathol ; 154:1621-6.

Merlo, A., J. G. Herman, et al. (1995). 5' CpG island methylation is associated with transcriptional silencing of the tumour suppressor p16/CDKN2/MTS1 in human cancers. Nat Med 1(7): 686-92.

Pufulete, M., R. Al-Ghnaniem, et al. (2005). Effect of folic acid supplementation on genomic DNA methylation in patients with colorectal adenoma. Gut 54(5): 648-653.

Ransohoff, D. F. (1988). Colon cancer in ulcerative colitis. Gastroenterology 94(4): 1089-91.

Risques RA, Lai LA, Brentall TA et al (2008). Ulcerative Colitis is a disease of accelerated colon ageing: evidence of from telomere attrition and DNA damage. Gastroenterology; 135:410-8

Risques RA, Lai LA, Himmetolgu C et al (2011). Ulcerative colitis associated colorectal cancer arises in a field of short telomeres, senescence and inflammation. Cancer Res. 2011 Mar 1;71(5):1669-79.

Rubin DT, LoSavio A, Yadron N et al (2006). Aminosalicylate therapy in the prevention of dysplasia and colorectal cancer in ulcerative colitis. Clin Gastroenterol Hepatol; 4(11):1346-50

Tahara, T., N. Inoue, et al. (2005). Clinical significance of microsatellite instability in the inflamed mucosa for the prediction of colonic neoplasms in patients with ulcerative colitis. Journal of Gastroenterology and Hepatology 20(5): 710-715.

Tominaga, K., S. Fujii, et al. (2005). Prediction of Colorectal Neoplasia by Quantitative Methylation Analysis of Estrogen Receptor Gene in Nonneoplastic Epithelium from Patients with Ulcerative Colitis. Clin Cancer Res 11(24): 8880-8885.

Usselmann B, Newbold M, Morris AG, et al (2001). Deficiency of colonic telomerase in ulcerative colitis. Am J Gastroenterol; 96:1106-12.

Van Guelpen, B., J. Hultdin, et al. (2006). Low folate levels may protect against colorectal cancer. Gut 55(10): 1461-1466.

Walmsley, R. S., R. C. S. Ayres, et al. (1998). A simple clinical colitis activity index. Gut 43(1): 29-32.

Wilson, A. S., B. E. Power, et al. (2007). DNA hypomethylation and human diseases. Biochimica et Biophysica Acta (BBA) - Reviews on Cancer 1775(1): 138-162. 


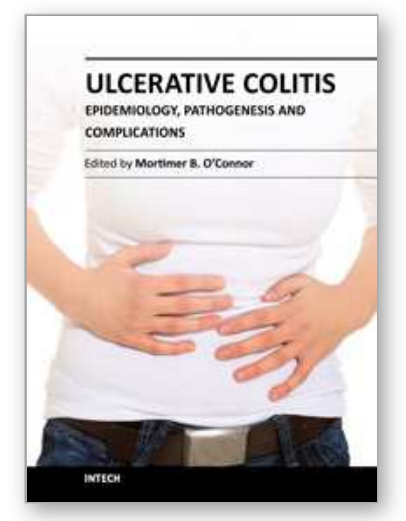

\author{
Ulcerative Colitis - Epidemiology, Pathogenesis and Complications \\ Edited by Dr Mortimer O'Connor
}

ISBN 978-953-307-880-9

Hard cover, 280 pages

Publisher InTech

Published online 14, December, 2011

Published in print edition December, 2011

This book is intended to act as an up-to-date reference point and knowledge developer for all readers interested in the area of gastroenterology and in particular, Ulcerative Colitis. All authors of the chapters are experts in their fields of publication, and deserve individual credit and praise for their contributions to the world of Ulcerative Colitis. We hope that you will find this publication informative, stimulating, and a reference point for the area of Ulcerative colitis as we move forward in our understanding of the field of medicine.

\title{
How to reference
}

In order to correctly reference this scholarly work, feel free to copy and paste the following:

Ramesh P. Arasaradnam and Chuka U. Nwokolo (2011). Molecular Determinants in Ulcerative Colitis Epigenetics and Telomere Dysfunction, Ulcerative Colitis - Epidemiology, Pathogenesis and Complications, Dr Mortimer O'Connor (Ed.), ISBN: 978-953-307-880-9, InTech, Available from:

http://www.intechopen.com/books/ulcerative-colitis-epidemiology-pathogenesis-and-complications/moleculardeterminants-in-ulcerative-colitis-epigenetics-and-telomere-dysfunction

\section{INTECH}

open science | open minds

\section{InTech Europe}

University Campus STeP Ri

Slavka Krautzeka 83/A

51000 Rijeka, Croatia

Phone: +385 (51) 770447

Fax: +385 (51) 686166

www.intechopen.com

\section{InTech China}

Unit 405, Office Block, Hotel Equatorial Shanghai

No.65, Yan An Road (West), Shanghai, 200040, China

中国上海市延安西路65号上海国际贵都大饭店办公楼 405 单元

Phone: +86-21-62489820

Fax: +86-21-62489821 
(C) 2011 The Author(s). Licensee IntechOpen. This is an open access article distributed under the terms of the Creative Commons Attribution 3.0 License, which permits unrestricted use, distribution, and reproduction in any medium, provided the original work is properly cited. 